\section{Abrasion Caused by Three Methods of Toothbrushing}

by

Allan D. PAdBuRY,* B.S., D.D.S., M.S.

MAJOR M. ASH, JR., ** D.D.S., M.S.

ABRASION RELATED to toothbrushing and dentifrices is present to some degree in most people who use toothbrushes and toothpastes. ${ }^{7}{ }^{14}$ The present concern for the abrasiviness of toothpastes ${ }^{5,32}$ also reflects a long term awareness of "toothbrush abrasion" $25-27$ which

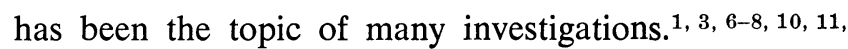
13-22, 24, 28, 30, 31, 34-36, 38 Initially studies dealt largely with the effects of dentifrices, ${ }^{3,6}, 11,15,16,17,36,38$ but later with the type, design and motion of hand brushes. $12,13,18,22,23,29,33,34,37$

Other factors associated with abrasion have been evaluated, including the amount of time spent brushing, force of brushing, slurry concentration, bristle size and diameter, speed of brushing motion, and effects of power brushes. ${ }^{1,2,9}, 10,17,19,20,21,24,28,30,31,35$ Although the results of many of the studies on abrasion are not easily compared, the development of an abrasivity index for dentifrices ${ }^{5}$ by the Council on Dental Therapeutics of the American Dental Association has provided some basis for standardization of dentifrices used in comparison studies of brushes, filaments and bristles. Although method and brush may not be as significant to abrasion as dentifrices, studies of toothbrush forces $2,4,9,23,28$ suggest that the force exerted by some patients may make method and filament or bristle type highly significant for individual control of abrasion.

Several investigators have concluded that a sweep or roll type motion produces less abrasion than a scrub type motion ${ }^{10,17}$ but the question of filament versus bristles relative to abrasivity has been reported in only a few studies. ${ }^{18,34}$ Differences in mechanical properties and cleaning effectiveness between filaments and bristles has received the most attention. ${ }^{12,13,29,33,37}$ Several investigators ${ }^{10,19,21,24,28,35}$ have compared the abrasive effects of power and manual brushing. The results of these studies, based on the use of more force with hand brushes, indicated that the power brushes studied were

\footnotetext{
*Assistant Professor, Department of Periodontics, The University of Michigan, School of Dentistry, Ann Arbor, Michigan 48104.

**Professor and Chairman, Department of Occlusion, The University of Michigan, School of Dentistry, Ann Arbor, Michigan 48104.
}

less abrasive than manual brushes under simulated brushing conditions. However, an in vivo telemetry study ${ }^{4}$ suggests that forces between hand and power brushes at the point of filament or bristle contact are essentially the same with considerable variation between patients for both methods of brushing.

The object of this study was to determine the abrasive effects of three methods of brushing (scrub, roll and powered ) with brushes having .009" diameter filaments and using a slurry from a dentifrice with an abrasivity index of $95(77-110) .^{5}$

\section{Methods}

The teeth used in this study were freshly extracted human teeth, consisting of maxillary and mandibular cuspids and incisors. The teeth were mounted in plastic and a uniform flat surface of dentin was exposed by grinding. The surface was then uniformly smoothed in a standardized series of polishing steps, beginning with medium sandpaper disks and continuing through a rubber cup and flour of pumice. Specimens that could not be prepared to the same uniform polished level were discarded. There were 90 teeth used in this study. Four one millimeter holes were drilled in the exposed dentin using a one half round bur. Two holes had an apical-incisal orientation and two had a mesial-distal orientation and were made $5 \mathrm{~mm}$. apart. These holes were made for reference points for a profile stylus connected to an X-Y recorder.

A power brush* and a standard manual brush** were the two types of brushes used. The manual brush was a soft, multi-tufted type consisting of four rows of 11 tufts each. The bristle diameter was 0.009 inch.

The power brush had an arcuate motion and operated at approximately 2,400 cycles per minute. A constant power supply was provided from a step down transformer to replace the battery power. Interchangeable brush heads with 0.009 inch diameter bristles were used on the power brush.

Toothbrushing machines were designed so that speed, stroke, length, and force of brushing could be varied.*** (Figure 1). One of the machines incorporated a back and forth (scrub) motion, while the other employed a roll or vertical type motion. The electric brush was prepared so that during testing, it could be mounted on the machine with a back and forth stroke.

A device was used for providing a uniform flow and mixture of a slurry dentifrice. The slurry consisted of

\footnotetext{
*Butler, "Torque 900".

**:Pro manual brush.

$*: *$ Sarnes, Inc., Ann Arbor, Michigan.
} 


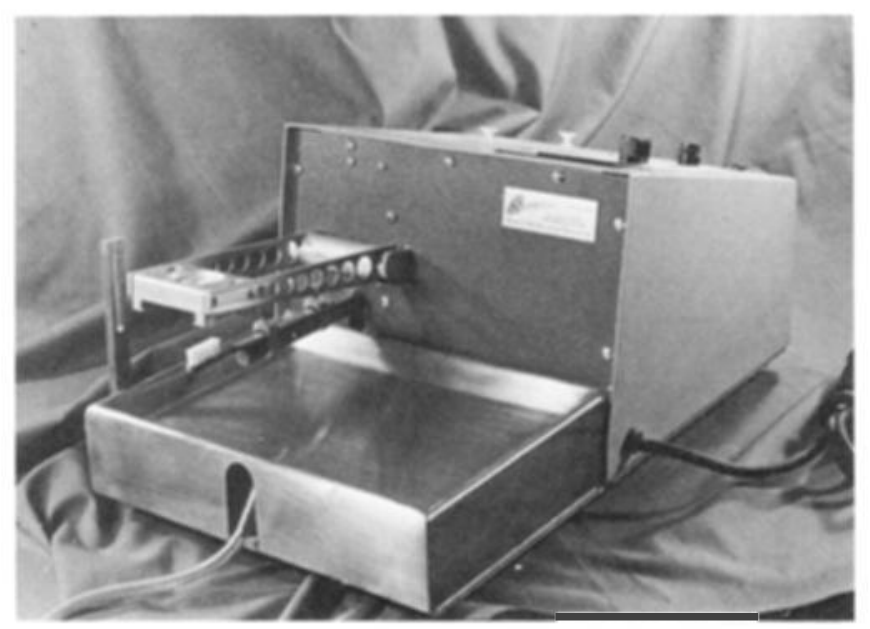

FIGURE 1. Toothbrushing machine.

two parts water and one part of a dentifrice that had an abrasivity index of 95 (77-110). 5

A modified $\mathrm{X}-\mathrm{Y}$ recorder and diamond stylus with a tracking force of 0.5 gram was used to record surface profiles on the dentin specimens and to provide a digital readout of integrated values for all profile changes from the initial base line values. With the instrumentation it was possible to measure integrated profile changes of 0.0001 inches or greater. The probe of the X-Y recorder was placed in an apically positioned reference mark (hole) and run to an incisally positioned mark. This procedure was repeated two more times. In addition, the same procedure was followed from the mesially to the distally positioned reference holes. Thus six profiles and integrated digital values were provided for each specimen prior to and after brushing.

Specimens were centered between the apically and incisally positioned reference holes and a load of 100 grams was applied to the electric brush and 200 grams to each of the manual brushes. A free flow of slurry was allowed to flow on the brushes and specimens.

The brushing machine simulating a manual roll method was run at 300 double strokes per minute. With this method the bristles moved parallel to the long axis of the tooth and through an arc of 110 degrees.

The machine simulating a scrub type manual brushing motion was run at 235 back and forth strokes per minute. With this method the bristles moved perpendicular to the long axis of the tooth through a one inch stroke.

The electric brush, while running at the normal 2400 cycles per minute, was moved back and forth through a one-half inch stroke 12 times per minute. This latter movement was incorporated to prevent "channeling" of the bristles and to more closely approximate intraoral movements of the brush.
Thirty teeth were selected by random number for each type of simulated brushing motion and each specimen was brushed for 30 minutes.

Two numerical values expressing amount of abrasion for each specimen were obtained: one from the vertical and one from the horizontal measurement. In addition, a third value was attained by averaging the horizontal and vertical values. The three values for each specimen in each of the three brushing groups were averaged.

One of the specimens in the automatic brushing group came loose from the plastic mounting during the after brushing profile run. Therefore, the values for one specimen in each of the other two brushing groups were eliminated by use of a random number table and the final statistical analysis based on $\mathrm{n}$ of 29 .

For each direction (vertical, horizontal and combined) an analysis of variance was performed to test for differences in method means. In addition, contrasts consisting of differences between pairs of method means were tested.

\section{RESULTS}

When the three brushing methods were tested for differences there was no statistically significant difference for the vertical direction of measurement $(p>.05)$ between the three groups (Table 1) but there was a significant difference for horizontal direction measurements (Table 2$)$ between the three groups $(p<.01)$. When the two values (horizontal and vertical) were averaged, the differences between the means for the three methods of brushing were significant at the 5 per cent level (Table 3 ).

TABLE 1.

Analysis of Variance: Methods of Brushing Direction of Measurement-Vertical

\begin{tabular}{lrrrr}
\hline $\begin{array}{l}\text { Source of } \\
\text { Variation }\end{array}$ & \multicolumn{1}{c}{$S S$} & $d f$ & \multicolumn{1}{c}{$M S$} & $F$ \\
\hline Between Groups & 47.809 & 2 & 23.904 & 2.872 \\
Among Groups & 699.268 & 84 & 8.235 & \\
Total & 747.077 & 86 & & \\
\hline
\end{tabular}

$\mathrm{F}=(.95)=3.11$

$F-(.99)=4.86$

TABLE 2.

Analysis of Variance: Methods of Brushing Direction of Measurement-Horizontal

\begin{tabular}{lrrrr}
\hline $\begin{array}{l}\text { Source of } \\
\text { Variation }\end{array}$ & \multicolumn{1}{c}{$S S$} & $d f$ & \multicolumn{1}{c}{$M S$} & $F$ \\
\hline Between Groups & 60.487 & 2 & 30.243 & 4.887 \\
Among Groups & 519.876 & 84 & 6.189 & \\
Total & 580.363 & 86 & & \\
\hline F $(.95)=3.11$ & & & & \\
F $(.99)=4.86$ & & & &
\end{tabular}


TABLE 3.

Analysis of Variance: Methods of Brushing Direction of Measurement $-\frac{\mathrm{H}+\mathrm{V}}{2}$

\begin{tabular}{lrrrr}
\hline $\begin{array}{l}\text { Source of } \\
\text { Variation }\end{array}$ & \multicolumn{1}{c}{$S S$} & $d f$ & \multicolumn{1}{c}{$M S$} & \multicolumn{1}{c}{$\boldsymbol{F}$} \\
\hline Between Groups & 53.899 & 2 & 26.949 & 4.684 \\
Among Groups & 483.349 & 84 & 5.754 & \\
Total & 537.248 & 86 & &
\end{tabular}

$\mathrm{F}(.95)=3.11$

$\mathrm{F}(.99)=4.86$

When mean abrasion values for pairs of brushing methods were compared using the method of contrasts (Student's t test), abrasion values were greater $(\mathrm{p}<.01)$ with the automatic and roll methods than with the scrub method (Table 4). There was no statistically significant difference in abrasion values between the automatic and roll methods $(\mathrm{p}>.05)$.

\section{Discussion}

The act of toothbrushing is extremely complex and in the presence of so many contributing variables an in vitro study of brushing is especially difficult. In this study several of the known variables were handled in a way comparable to the way they had been in previous, similar investigations ${ }^{10,21,28,35}$ for comparison purposes.

A superimposed stroke on the normal, rapid oscillations of the powered brush has been used in previous experiments. ${ }^{10,21,24,28,35}$ The rationale given for providing this additional movement varies from study to study, viz., to simulate normal oral movements of the brush, ${ }^{10,28,35}$ to prevent "channeling" of the bristles, ${ }^{21}$ and to prevent "stradling" of the specimens by brush

TABLE 4.

Analysis of Between Group Differences (Brushing Methods)

\begin{tabular}{llccc}
\hline & Automatic & Roll & Scrub & Total \\
\hline Vertical & x 3.723 & 3.560 & 2.076 & X 3.12 \\
Measurement & n 29 & 29 & 29 & N 87 \\
Horizontal & x 3.222 & 3.216 & 1.450 & X 2.63 \\
Measurement & n 29 & 29 & 29 & N 87 \\
H + V & x 3.475 & 3.391 & 1.765 & X 2.88 \\
\multicolumn{1}{c}{2} & n 29 & 29 & 29 & N 87 \\
\hline
\end{tabular}

Automatic vs. Scrub: $\quad t=2.71$

$\mathrm{df}=84$

$\mathrm{p}<0.01$

Automatic vs. Roll: $\quad \mathrm{t}=0.127$

$\mathrm{df}=84$

$\mathrm{p}-$ N.S.

Roll vs. Scrub: $\quad t=2.60$

df $=84$

$\mathrm{p}<0.01$ bristles. ${ }^{24}$ Although such precautions have been taken with regard to the powered and not the manual brushes, it would seem that a similar superimposed movement of the brush or specimen in the case of simulated manual brushing would be necessary to maintain consistency. Trial portions of this study demonstrated that if no stroke was superimposed on the power brush, deep patterns of wear or "ruts" developed. The bristles then tended to be restricted to these "ruts" and exaggerated abrasion and gross roughness resulted. However, the same was true with the simulated scrub method. Nevertheless, to maintain uniformity of method and results with previous studies, no superimposed movement was incorporated into the simulated scrub method. Also for the same reason the stroke speed for both the simulated roll and scrub methods utilized in this study was that used in several other investigations. ${ }^{10,} 28,35$

The amount of abrasion has been reported to be directly proportional to brushing time. ${ }^{1}$ In this study onehalf hour tests were conducted as it was noted that this time period was sufficient to produce significant measurable effects. Other studies have used different brushing times. ${ }^{10,19,21,24,28,34}$

The slurry was diluted with two parts water as in other experiments. ${ }^{1,10,16,17.24,28,35}$ It must be assumed that some dilution of dentifrice with saliva takes place in the normal situation.

It has been ascertained that force applied to the brush head is an important factor in the production of abrasion. ${ }^{19,}{ }^{28}$ Several studies have reported on the averaged forces utilized in normal brushing 2, 4, 9, 23, 28 and force values have varied widely. In order to compare our results with those of other studies, the toothbrushing force values that have been reported for strain gauges or other measuring devices placed in the brush handles, ${ }^{2,9,28}$ were used in the present study. Thus, the brushing force used with the power brush was 100 gms. and 200 gms. for the manual brushes.

It was found in the present study that the scrub technique of brushing produced significantly less abrasion than did the simulated roll or powered brushing (Table 3 ) and is contrary to previous findings. ${ }^{10,17}, 19,21,28,35$ The roll method produced generalized abrasion whereas the scrub method produced rather extensive localized visible abrasion. The generalized wear, however, added up to a greater total of wear.

Manly, et al. ${ }^{21}$ have pointed out that it is important to distinguish between deep grooves (localized heavy abrasion) and generalized minor abrasion. Although the roll method produced greater total abrasion, the localized "grooving" that occurred with the scrub method could be considered more unsatisfactory in the in vivo situation. 


\section{SUMMARY}

A comparative evaluation of the abrasive effects of an arcuate motion powered toothbrush and two simulated, commonly employed methods of hand brushing was carried out on extracted human teeth.

Ninety specimens were randomly divided into three groups; each group was subjected to one of the three brushing methods.

There was greater total abrasion produced by simulated roll and power brushing than with simulated scrub brushing although localized abrasion ("grooving") was greater in the latter.

There was no significant difference in amount of abrasion produced by the simulated roll and powered method, but there was more localized abrasion with the latter method of brushing.

\section{CONCLUSIONS}

Under the conditions of this study, it is concluded that:

(1) The manual roll method of brushing and an arcuate motion powered toothbrushing method produce an equal amount of total surface abrasion.

(2) The manual roll method of brushing and an arcuate motion powered toothbrushing method both produce more total surface abrasion than the manual scrub method.

(3) The roll method of brushing produces less localized abrasion ("grooving," "rutting") than the scrub method of brushing.

\section{REFERENCES}

1. Björn, H. and Lindhe, J.: Abrasion of dentin by toothbrush and dentifrice. Odont. Revy., 17:17-27, 1966.

2. Björn, H., and Lindhe, J.: On the mechanics of toothbrushing. Odont. Revy., 17:9-16, 1966.

3. Bunting, R. and Rickert, V. G.: Dental Caries. Nat. Dent. A. J., 2:247-269, Aug. 1915.

4. Burgett, F. G., and Ash, M. M., Jr.: Comparative study of the pressure of brushing with three types of toothbrushes. Submitted for publication, April 1973.

5. Council on Dental Therapeutics. Abrasivity of current dentifrices. J. Amer. Dent. Assoc., 1177-8, Nov., 1970.

6. Epstein, S., and Tainter, M. L.: Abrasion of teeth by commercal dentifrices. J. Amer. Dent. Assoc., 30:10361045, 1943.

7. Ervin, J. C., and Bucher, E. M.: Prevalence of tooth root exposure and abrasion among dental patients. Dent. Items of Interest, 66:760-769, Aug., 1944.

8. Ferrier, W. I.: Clinical observations on areas of erosion and their restoration. Am. Dent. A. J., 20:11501163, July 1933.
9. Fraleigh, C. M., McElhaney, J. H., and Heiser, R. A.: Toothbrushing force study. J. Dent. Res., 46:209214, Jan.-Feb., 1967.

10. Harrington, J. H. and Terry, I. A.: Automatic and hand toothbrushing abrasion studies. Am. Dent. A. J., 68:343-350, Mar., 1964.

11. Head, J.: Modern Dentistry. W. B. Saunders and Co., Philadelphia, Pa., 1917. p. 60

12. Hine, M. K., Jr.: Variation in toothbrush textures. Am. Dent. A. J., 46:536-539, May 1953.

13. Hine, M. K., Wachtl, C., and Fosdick, L. S.: Some observations on the cleansing effect of nylon and bristle toothbrushes. J. Periodontol., 25:183-188, July 1954.

14. Kitchin, P. C.: The prevalence of tooth root exposure and the relation of the extent of such exposure to the degree of abrasion in different age classes. J. Dent. Res., 20:565-581, Dec. 1941

15. Kitchin, P. C., and Robinson, H. B. G.: The abrasiveness of dentifrices as measured on the cervical areas of extracted teeth. J. Dent. Res., 27:195-200, Apr.-May 1948.

16. Manly, R. S.: Abrasion of cementum and dentin by modern dentifrices. J. Dent. Res., 20:583-595, Dec. 1941.

17. Manly, R. S.: Factors influencing tests on the abrasion of dentin by brushing with dentifrices. J. Dent. Res., 23:59-72, Feb. 1944.

18. Manly, R. S., and Brudevold, F.: Relative abrasiveness of natural and synthetic toothbrush bristles on cementum and dentin. Am. Dent. A. J., 55:779-780, 1957.

19. Manly, R. S., and Foster, D. H..: Importance of factorial designs in testing abrasion by dentifrices. J. Dent. Res., 46:442-445, Mar.-Apr. 1967.

20. Manly, R. S., and Foster, D. H.: Improvement in methods for measurement of abrasion of dentin by toothbrush and dentifrice. J. Dent. Res., 45:1882, Nov.-Dec. 1966.

21. Manly, Wiren, Manly, and Keene: A method for measurement of abrasion of dentin by toothbrush and dentifrice. J. Dent. Res., 44:533-40, 1965.

22. Mannerberg, F.: Appearance of tooth surface as observed in shadow replicas in various age groups, in long-term studies, after toothbrushing, in cases of erosion, and after exposure to citrus fruit juice. Odont. Revy., 2:70$86,1960$.

23. McCauley, H. B.: Toothbrushes, toothbrush materials and design. Am. Dent. A. J., 33:283-293, Mar. 1946.

24. McConnell, D., and Conroy, C. W.: Comparisons of abrasion produced by a simulated versus a mechanical toothbrush. J. Dent. Res., 46:1022-1027, Sept.-Oct., 1967.

25. Miller, W. D.: Experiments and observations on the wasting of tooth tissue variously designated as erosion, abrasion, chemical abrasion, denudation, etc. Dent. os., 49:1-23, Jan. 1907.

26. Ibid. Dent. Cos., Feb. 1907.

27. Ibid. Dent. Cos., 225-247, Mar. 1907.

28. Phaneuf, E. A., Harrington, J. H., Dale, P. P., and Shklar, G.: Automatic toothbrush: A new reciprocating acion. Am. Dent. A. J., 65:12-25, 1962.

29. Phillips, R. W., and Swartz, Marjorie: Effects of diameter of nylon bristles on enamel surface. Am. Dent. A. J., 47:20-26, July 1953.

30. Robinson, H. B. G.: Toothbrushing habits of 405 persons. Am. Dent. A. J., 33:1112-1117, Sept. 1946.

31. Smith, J. L.: Value of the antimony plate abrasion apparatus in testing dentifrice abrasives. Am. Dent. A. J., 26:206-210, Feb. 1939.

32. Stookey, G. K. and Muhler, J. C.: Laboratory 
studies concerning the enamel and dentin abrasion properties of common dentifrice polishing agents. J. Dent. Res., 47:524-32, July-Aug. 1968.

33. Swartz, M. L, Phillips, R. W., and Hine, M. K.: effect of certain factors upon toothbrush bristle stiffness. J. Periodontol., 27:96-101, Apr. 1956.

34. Tainter, M. L., and Epstein, S. A.: A standard procedure for determining abrasion by dentifrices. J. Amer. Coll. Dent., 9:353-79, 1942.

35. Terry, I. A., and Harrington, J. B.: Abrasion tests on acrylics. Am. Dent. A. J., 65:377, Sept. 1962.

36. Van Der Mërwe, S. W.: Some aspects of modern dentifrices. J. Dent. Res., 7:327-336, Sept. 1927.

37. Wade, A. B.: A clinical assessment of the relative physical properties of nylon and bristle brushes. Brit. Dent. J., 114:260-264, May 1953.

38. Wright, H. H., and Fenske, E. L.: Relative abrasive properties of the more commonly used dentifrice abrasives. Am. Dent. A. J., 24:1889-1895, 1937.

\section{Abstracts}

\section{The State of Calcium and Inorganic Orthophosphate IN Human Saliva}

Grøn, P.

Arch. Oral Biol., 18:1365, 1973.

The products of both resting and stimulated salivary glands were studied for the state of calcium and inorganic orthophosphate. In resting parotid saliva the mean findings showed: $85 \%$ of the calicum was ionized, $8 \%$ was bound to macromolecules, and $6 \%$ was in ion pairs. In stimulated secretions the ionized calcium ranged from $45-54 \%$, the fraction bound to macromolecules amounted to $30-43 \%$, and the calicum in ion pairs was $12-17 \%$. The ultrafiltrability of inorganic orthophosphate was between 66 and $70 \%$ in stimulated salivas and over $90 \%$ in resting parotid saliva. The ultrafiltrable phosphate was almost totally ionized because only $1-2 \%$ was complexed with calcium. Forsyth Dental Center, Boston, Mass. 02115.

\section{The Permeability of Keratinized and Nonkeratinized Oral Epithelium to Horseradish Peroxidase}

Squier, C. A.

J. Ultrastruct. Res., 43:160, 1973.

A series of experiments was conducted in which horseradish peroxidase was used as an ultrastructural tracer and either applied topically or introduced subepithelially into both keratinized and nonkeratinized oral epithelium of albino Wistar rats, large white rabbits, and Macaque monkeys, and its subsequent fate was followed with the electron microscope. When introduced subepithelially, the penetration of peroxidase into both keratinized and nonkeratinized epithelium occurred at the same rate and to a similar extent independent of quantity of material or time of contact. It was also noted that peroxidase was visible in the connective tissue and extended through the intercellular spaces of the epithelium, more specifically into the granular layer of keratinized epithelium and the "intermediate" cell region of nonkeratinized epithelium. In both types the appearance of "membrane coating granules" at the cell membranes was coincident with the limit of penetration, suggesting perhaps that these granules secrete an intercellular barrier. After surface application, both keratinized and, surprisingly, nonkeratinized epithelium exhibited relatively little permeability, penetration rarely exceeding the upper 2 to 3 rows of cells. These experiments suggest that intercellular material may constitute a primary permeability barrier. Department of Oral Pathology, The London Hospital Medical College, Turner Street, London, E.I., England.

\section{EFFECT OF NUTRITIONAL HYPERPARATHYROIDISM ON Experimental Periodontitis In the Dog}

Svanberg, G., Lindhe, J., Hugoson, A., and Gröndahl, H.-G. Scand. J. Dent. Res., 81:155 1973.

Beagle dogs were used to investigate the possibility of inducing: (1) osteopenia of the alveolar process by nutritional secondary hyperparathyroidism (NSH-calcium-deficient, phosphorous-rich diet), (2) increased tooth mobility in animals suffering from NSH, and (3) chronic gingivitis and marginal periodontitis in the absence of microbial plaque in dogs with NSH. Although NSH and osteopenia were induced, an increased tooth mobility as had been reported in other studies did not result, and an obvious decrease in horizontal tooth mobility was observed. Dogs in the NSH state and normal dogs demonstrated no gingivitis in the absence of microbial plaque, as determined by gingival exudate measurements, whereas, where plaque was allowed to accumulate, both test and control animals demonstrated gingivitis. Similarly, no pathologic pockets developed in either test or control dogs in the absence of plaque. It was concluded that the major etiological factor in the development of gingivitis and marginal periodontitis was dental plaque. Alveolar osteopenia induced by NSH seemed to be of no importance for the initiation and rate of progression of periodontal disease as defined in this study. Department of Periodontology, Faculty of Odotology, Fack, S-400 33 Gothenburg, Sweden.

\section{Temporomandibular Pain-Dysfunction and OCClusal RELATIONSHIP}

Roth, R. H.

Angle Orthodont., 43:136, 1973.

A discussion of the identification and elimination of occlusal interferences which have a causal relationship to temporomandibular pain-dysfunction was presented. Nine patients who had completed orthodontic therapy were selected for this study. Of these seven were selected because of need for symptom relief, while two that were symptom-free were considered controls. Data including pantographic tracings and interocclusal wax records were obtained from each. The findings indicated a correlation between balancing interferences and temporomandibular pain-dysfunction symptoms. A centrically related, mutually protected occlusion adjustment was described and shown to be effective in correcting occlusally-induced temporomandibular pain-dysfunction syndrome. $401 \mathrm{~N}$. San Mateo Drive, San Mateo, California 94401. 